\title{
Platform process will give platform product - Can we afford it?
}

\author{
Rohit Diwakar*, Sunaina Prabhu, Lavanya C Rao, Janani Kanakaraj, Kriti Shukla, Saravanan Desan, Dinesh Baskar, \\ Ankur Bhatnagar, Anuj Goel \\ From 23rd European Society for Animal Cell Technology (ESACT) Meeting: Better Cells for Better Health \\ Lille, France. 23-26 June 2013
}

\section{Introduction}

Manufacturing processes for therapeutic monoclonal antibodies (mAbs) have evolved immensely in the past two decades around two major thrust areas.

1) Advancements in a) Cell line developmentbreakthrough and incremental knowledge gain in technology b) Media and feed formulation strategies c) Advent of Disposables and Instrumentation technologies thus offering significant improvements to Process Development (PD).

2) Establishment of platform processes to leverage faster PD $[1,2]$.

A platform process generally consists of a standard i) Cell line development technique, ii) Basal medium and feeds, iii) Process parameters and scale-up approach. The biggest advantage of using the platform process for the PD group is in expediting the project timelines. The platform approach also benefits from well-established and validated work flows in Manufacturing, QA, QC and Supply-chain groups.

Certain disadvantages have also been cited for the platform approach. For example, modifications in the platform process are generally discouraged due to time, cost and efforts required in accommodating such changes. Also, as process conditions can substantially impact the product quality (PQ) attributes, a platform approach does not allow any significant changes in the PQ attributes, if desired.

\section{Materials and methods}

In this study, $\mathrm{CHO}$ cell lines were cultured in chemically defined medium. Experiments were carried out in 2L stirred tank bioreactors and $125 \mathrm{~mL}$ shake flasks running at

\footnotetext{
* Correspondence: rohit.diwakar@biocon.com

Cell Culture Lab, Biocon Research Limited, Bangalore, India
$140 \mathrm{rpm}$ in $5 \% \mathrm{CO}_{2}$ controlled incubator shaker. Cell count and viability were determined using haemocytometer. Lactate, glucose, osmolality and IgG concentration was also estimated along with glycosylation profiling.

\section{Results and discussion}

Case 1: Multiple cell lines developed using same technology expressing different mAbs

Using the same cloning technology, cell lines expressing mAbs 1-4 were developed. These cell lines when run with the platform process showed very similar growth, titer and glycosylation profiles. Glycan profile thus produced is represented as three species; type I, II and III.

The advantage of platform process was evident from the similarity of glycan profiles achieved in all the mAbs run with this process. However, for mAbs 3 and 4, the target glycan profile was significantly different. The platform process gave $20-30 \%$ higher glycan type 1 than the respective targets. In order to match the targeted glycan profile, a few changes were made:

i) mAb 3: New feed introduced to reduce glycan type 1 ; feeding strategy was optimized during PD.

ii) $\mathrm{mAb} 4$ : In addition to feeding strategy used for $\mathrm{mAb3}$, changes in process parameter ( $\mathrm{pH}$ and $\mathrm{DO})$ set-points were done to achieve desired glycosylation profiles.

Case 2: Difference in lead clone selection criteria - growth vs. specific productivity

Clone selection is done by ranking the clones based on parameters such as cell growth, titer, specific productivity (PCD) and PQ. In this study, the lead clones were shortlisted based on different strategies. For mAbs 1-4, the lead clone was shortlisted based on cell growth and 


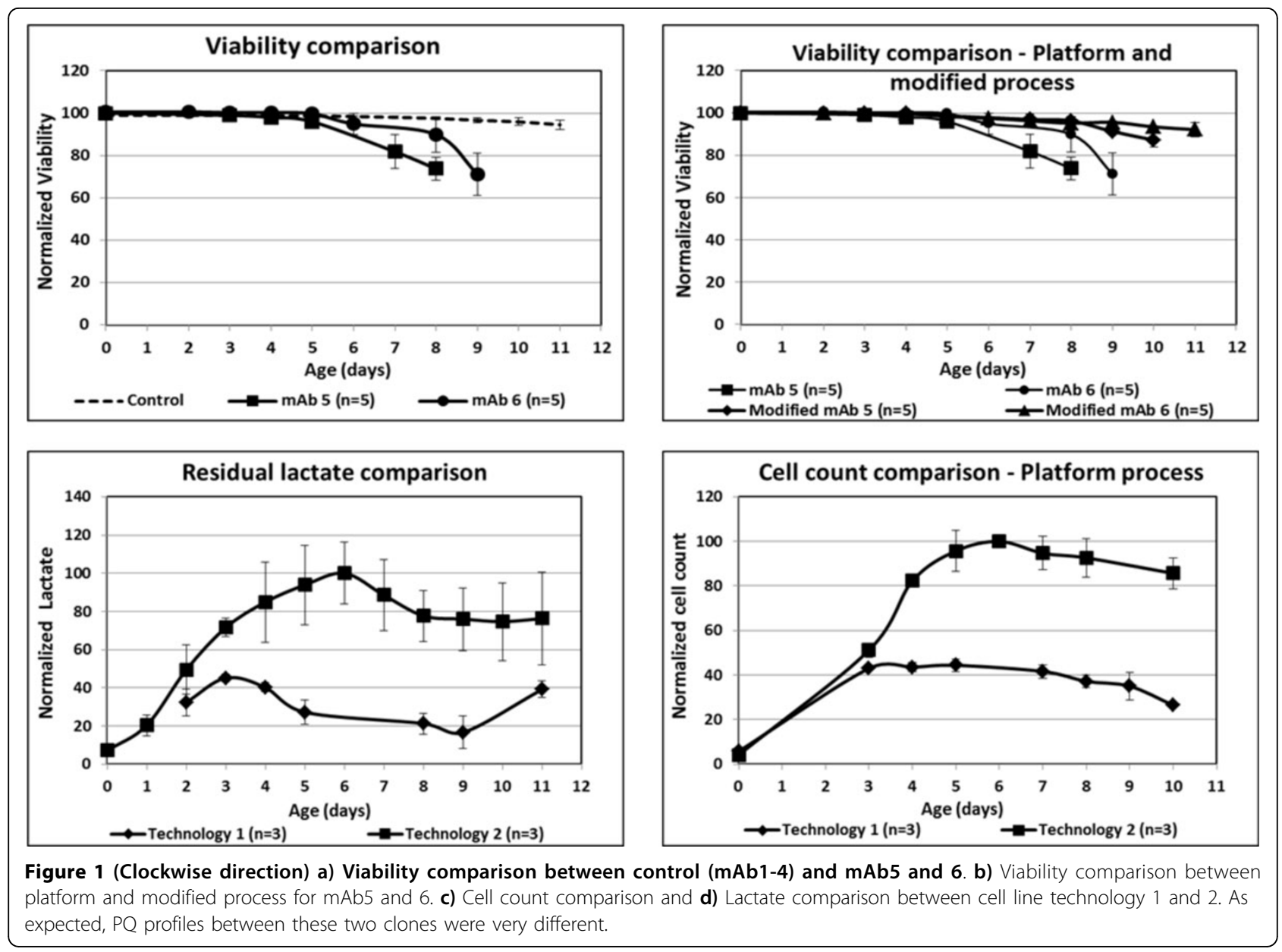

titer as dominant selection criteria. For mAbs 5 and 6, PCD was the dominant selection criterion. The other aspects of the cloning technique were same in all cell lines.

When lead clones for mAb 5 and 6 were run in platform process they showed poor growth characteristics (Figure 1a). The early drop in viability made these clones unfit for a manufacturing process. Changes in the platform process were attempted to overcome this manufacturing concern:

i) mAb 5: Culture longevity was increased by restricting cell growth. This was achieved by reducing nutrient levels in the production medium.

ii) mAb 6: Lactate and ammonia accumulation was reduced by optimizing medium/feed composition and $\mathrm{pH}, \mathrm{DO}$ control ranges.

The modified processes significantly improved the culture longevity and viability profiles, making them suitable for manufacturing (Figure 1b).
Case 3: Cell lines expressing the same mAb developed using different technology

Two cloning technologies, 1 and 2 were used to develop clones expressing the same mAb. The major differences in the technologies were i) host cell lines ii) design of vector and its mechanism in the genome. Both cell lines were run with the same platform process and a two-fold difference in cell count was observed between them (Figure 1c). The lactate levels were also markedly different (Figure 1d), possibly indicating differences in nutrient metabolism. The lactate differences also reflected in the $\mathrm{pH}$ profiles.

\section{Summary}

Case 1: The use of platform process enabled accelerated PD from cell culture perspective. However, accommodating the specific $P Q$ requirements resulted in extended process development, affecting timelines.

Case 2: Change in clone selection criteria was observed to significantly impact culture performance while applying platform process. This almost resulted in 
rejection of these clones, thus extending PD timelines. This was prevented by modifying the platform process.

Case 3: Clones developed using different cloning technologies when run with the platform process resulted in different cell culture and PQ profiles. Therefore, the type of cloning technique forms an integral part of the platform process.

Though platform process was not suitable in most of the cases discussed here, it still offers advantages like expedited project timelines and established work flows. These benefits were achieved by establishing four versions of the platform process to meet the varied cell culture and PQ requirements. Based on the cell line characteristics and target $\mathrm{PQ}$ profiles, the appropriate version is chosen to initiate $\mathrm{PD}$. These versions retained the major advantages of the platform process such as having common media and feeds with only changes in their concentrations and set point of main process parameters to achieve desired PQ.

\section{Acknowledgements}

Cell Culture Lab - Ruchika Srivastava, Vana Raja S, Chandrashekhar K.N

Characterization Lab - Varshini Priya, Laxmi Adhikari

Purification Lab - Shashank Sharma

Published: 4 December 2013

\section{References}

1. Kelley B: Industrialization of mAb production technology. Landes Biosciences 2009, 5:443-452, mAbs 1.

2. Li F, Vijayasankaran N, Shen A, Kiss R, Amanullah A: Cell culture processes for monoclonal antibody production. Landes Biosciences 2010, 5:466-477, mAbs 2.

\section{Submit your next manuscript to BioMed Central} and take full advantage of:

- Convenient online submission

- Thorough peer review

- No space constraints or color figure charges

- Immediate publication on acceptance

- Inclusion in PubMed, CAS, Scopus and Google Scholar

- Research which is freely available for redistribution

Submit your manuscript at www.biomedcentral.com/submit 